\title{
Effect of Laser Processing Parameters on the Formation of Intermetallic Compounds in Fe-Al Dissimilar Welding
}

Sonia Meco, Supriyo Ganguly, Stewart Williams, and Norman McPherson

\author{
(Submitted March 4, 2014; in revised form May 15, 2014; published online June 18, 2014)
}

\begin{abstract}
Fusion welding of steel to aluminum is difficult due to formation of different types of Fe-Al intermetallics (IMs). In this work, $2 \mathrm{~mm}$-thick steel was joined to $6 \mathrm{~mm}$ aluminum in overlap configuration using a $8 \mathrm{~kW}$ CW fiber laser. A defocused laser beam was used to control the energy input and allow melting of the aluminum alone and form the bond by wetting of the steel substrate. Experimentally, the process energy was varied by changing the power density (PD) and interaction time separately to understand the influence of each of these parameters on the IM formation. It was observed that the IM formation is a complex function of PD and interaction time. It was also found that the mechanical strength of such joint could not be simply correlated to the IM layer thickness but also depends on the area of wetting of the steel substrate by molten aluminum. In order to form a viable joint, PD needs to be over a threshold value where although IM growth will increase, the strength will be better due to increased wetting. Any increase in interaction time, with PD over the threshold, will have negative effect on the bond strength.
\end{abstract}

Keywords aluminum, dissimilar welding, intermetallic compounds, laser, steel

\section{Introduction}

For many years the joining of dissimilar metals has been investigated with particular interest in the bi-metallic combination of steel and aluminum. The possibility of tailoring the structures through the combination of materials with different physical and mechanical properties is very attractive to the transportation sector, such as shipbuilding and automotive industries. The structural optimization by the improvement of the ratio between weight and strength leads to a new generation of lighter vehicles with better dynamic performances and lower fuel consumption. The latter is also important to comply with the new stricter environmental legislations regarding the $\mathrm{CO}_{2}$ emissions.

The main issue associated with the dissimilar metal joining of steel to aluminum is the formation of the brittle intermetallic (IM) compounds, which result from the reaction between iron (Fe) and aluminum (Al) during the joining process. The $\mathrm{Fe}-\mathrm{Al}$ IM compounds usually form a continuous layer at the interface between the steel and aluminum plates which is detrimental to the integrity of the joint. The growth of the layer starts even

Sonia Meco, Supriyo Ganguly, and Stewart Williams, Welding Engineering and Laser Processing Centre, Cranfield University, University Way, Building 46, Cranfield, Bedfordshire MK43 0AL, UK; and Norman McPherson, BAE Systems Maritime - Naval Ships, 1048 Govan Road, Glasgow G41 5XP, UK. Contact e-mails: s.a.martinsmeco@ cranfield.ac.uk, s.ganguly@cranfield.ac.uk, s.williams@cranfield. ac.uk, and norrie.mcpherson@baesystems.com.

\begin{tabular}{|ll|}
\hline & \multicolumn{1}{|c|}{ List of symbols } \\
\hline $\mathrm{Fe}$ & Iron \\
$\mathrm{A} 1$ & Aluminum \\
$\mathrm{IM}$ & Intermetallic \\
$\mathrm{FMIP}$ & Fundamental material interaction parameters \\
$E_{\mathrm{sp}}$ & Specific point energy $(\mathrm{kJ})$ \\
$P$ & Laser power $(\mathrm{kW})$ \\
$\mathrm{TS}$ & Travel speed $\left(\mathrm{cm} \mathrm{min}^{-1}\right)$ \\
$D_{\text {beam }}$ & Laser beam diameter $(\mathrm{mm})$ \\
$\mathrm{PD}$ & Power density $\left(\mathrm{kW} \mathrm{cm}^{-2}\right)$ \\
$t_{\mathrm{i}}$ & Interaction time $(\mathrm{s})$ \\
$A_{\text {beam }}$ & Laser beam area $\left(\mathrm{cm}^{-2}\right)$ \\
& \\
\hline
\end{tabular}

when the processing temperature is lower than the melting temperature of the aluminum (Ref 1$)$. It is known that the formation of the IM compounds is mainly controlled by the temperature and the time $(\operatorname{Ref} 2,3)$, therefore, the choice of a joining process is important for the success of the joint. According to some researchers, the joining process should have simultaneously low heat input and high cooling rate (Ref 4).

The research on dissimilar metal joining of steel to aluminum is extensive, in which several joining processes and different grades of steel and aluminum have been used. However, these studies have mainly focused on material thicknesses about $1 \mathrm{~mm}$, aimed for the automotive industry. In the maritime industry, the structures are usually made of metals more than $2 \mathrm{~mm}$ thick which require higher energy for joining. This is an additional challenge for dissimilar joints. Nowadays, to overcome the formation of the Fe-Al IM compounds, a bi-metallic transition bar, made of steel and aluminum and produced by explosion welding ( Ref 5), is used in between the main structural frames. Thus, the joint is produced by welding the steel and the aluminum substrates directly to the steel and aluminum sides of the transition bar, 
respectively, leading to strong joints (Ref 6). However, this approach is not cost effective in terms of material, processing time, and logistics and significant benefit could be achieved if the intermediate composite bar can be eliminated by direct joining of steel and aluminum.

Laser, as a high power density (PD) heat source, offers significant advantages in terms of low heat input and resulting lowering in component distortion (Ref 7). Laser beam can also be applied with high precision in positioning resulting controlled mixing of the participating alloys. The other advantage of laser is controlled application of laser power, in conduction mode, whereby the applied energy raises the temperature of the substrate at a controlled rate. In conduction mode of laser welding weld pool temperature is maintained below the vaporization point which helps in achieving a stable and controlled welding process (Ref 8). This principle is predominantly applied in the reported work, where laser applied on the steel substrate, in Fe-Al overlap configuration, melts the aluminum only in the interface and creates the bond. This is vital in restricting diffusion between the two alloys and therefore, formation of IM compounds. Fan et al. (Ref 9) correlated the IM layer growth with the laser power and the transient thermal cycle which shows a non-linear relationship of IM layer growth with laser power and the transient thermal cycle, however, the paper did not distinguish the effect of temperature and time.

Most of the researchers, emphasized on the laser system parameters viz. the laser power $(P)$, travel speed (TS), and spot size $\left(D_{\text {beam }}\right)$ where the effect of spot size is often not investigated. However, these system parameters are interdependent and the variation in resulting thermal cycle is not a simple function of either of these parameters. This also may cause non-reproducibility of results due to difference in individual laser characteristics (Ref 10). In order to overcome this, PD, interaction time $\left(t_{\mathrm{i}}\right)$, and specific point energy $\left(E_{\mathrm{sp}}\right)$ are introduced in this study as fundamental material interaction parameter (FMIP), as shown in (Eq 1-3), and the dependency of joint strength and IM layer on FMIP are analyzed. The FMIPs are calculated based on the system parameters and correspond to the physical interaction of the laser energy with the material (Ref 11).

$\mathrm{PD}\left(\mathrm{kW} \mathrm{cm}^{-2}\right) \quad \mathrm{PD}=P \cdot A_{\text {beam }}^{-1}$.

Interaction time $(\mathrm{s}) \quad t_{\mathrm{i}}=D_{\text {beam }} \cdot \mathrm{TS}^{-1}$.

Specific point energy $(\mathrm{kJ}) \quad E_{\mathrm{sp}}=\mathrm{PD} \times t_{\mathrm{i}} \times A_{\text {beam }}$.

PD corresponds to heat flux or power per unit area of the incident laser beam. $t_{\mathrm{i}}$ is calculated by the spot size $\left(D_{\text {beam }}\right)$ divided by the TS and represents the heating time of an infinitesimal element within the laser spot. Finally, $E_{\mathrm{sp}}$ is calculated from the product of PD by $t_{\mathrm{i}}$ and by the area of the laser beam $\left(A_{\text {beam }}\right)$ and represents the total energy transferred to the work piece through the incident laser spot.

As discussed in the previous paragraph, lap weld between 2 mm-thick XF350 steel plate on 6 mm-thick AA5083 aluminum alloy plate was reported here where the joint was formed by wetting the steel substrate by molten aluminum at the interface. Laser energy was applied on the steel substrate and conducted through the steel to the interface where it melts the aluminum. The aim of the work is to understand the influence of each of the FMIP on the Fe-Al IM layer thickness and the resulting joint strength for thicker sections.

\section{Materials and Experimental Details}

\subsection{Materials}

Plates of high strength low alloy steel (XF350) having a thickness of $2 \mathrm{~mm}$ and plates of aluminum, grade AA5083, with the thickness of $6 \mathrm{~mm}$ were used. The dimension of the plates $(150 \mathrm{~mm} \times 138 \mathrm{~mm})$ was based on the standard EN ISO 14273:2001 for shear testing resistance seam welds. Tables 1 and 2 show the chemical composition and physical properties of the alloys, respectively.

All plates were cleaned before starting the joining process. The steel plates were ground to remove the oxides from the surface and the aluminum plates were linished to eliminate the alumina. Afterward all plates were degreased with acetone.

\subsection{Laser Welding Process with Solid-Liquid Interface}

The joints were produced using an IPG fiber laser with $8 \mathrm{~kW}$ of maximum power and wavelength of $1.07 \mu \mathrm{m}$. The continuous wave (CW) laser was operated in conduction mode with a large and defocused laser beam. The window of parameters used in the experimental work is given in Table 3, for both, system parameters and FMIP.

The experimental setup is shown in Fig. 1. A robot was used on which the laser head was mounted and the specimen was clamped on the gantry system. In these experiments, the robot arm was kept stationary while the gantry moved to create the linear welds.

Table 2 Mechanical properties of the base materials

\begin{tabular}{lccc}
\hline Material & $\begin{array}{c}\text { Yield } \\
\text { strength, MPa }\end{array}$ & $\begin{array}{c}\text { Ultimate tensile } \\
\text { strength, MPa }\end{array}$ & $\begin{array}{c}\text { Total elongation } \\
\text { at failure, \% }\end{array}$ \\
\hline XF350 & 368 & 474 & 23 (at $80 \mathrm{~mm})$ \\
$5083-\mathrm{H} 22$ & 250 & 337 & 8 (at $50 \mathrm{~mm})$ \\
\hline
\end{tabular}

Table 1 Chemical composition of the base materials

\begin{tabular}{|c|c|c|c|c|c|c|c|c|c|c|c|c|c|}
\hline \multirow[b]{2}{*}{ Material } & \multicolumn{13}{|c|}{ Elements (wt.\%) } \\
\hline & Al & $\mathrm{Fe}$ & $\mathbf{C}$ & $\mathbf{S i}$ & Mn & $\mathbf{P}+\mathbf{S}$ & $\mathbf{N i}$ & $\mathbf{T i}$ & $\mathbf{C u}$ & Mg & $\mathbf{Z n}$ & $\mathrm{Cr}$ & Other \\
\hline XF350 & 0.047 & Bal. & 0.059 & 0.021 & 0.610 & 0.025 & 0.020 & 0.001 & 0.03 & $\ldots$ & & 0.030 & 0.255 \\
\hline $5083-\mathrm{H} 22$ & Bal. & 0.400 & $\ldots$ & 0.400 & 0.500 & $\ldots$ & $\ldots$ & 0.150 & 0.100 & $2.600-3.600$ & 0.200 & 0.300 & $\ldots$ \\
\hline
\end{tabular}


In this experimental setup, the steel was positioned on top of the aluminum in a lap joint configuration, and was illuminated by the laser. The heat conducted through the steel, melts the aluminum which in turn wets the steel (solid-liquid interface). In this process, the temperature on the $\mathrm{Fe}-\mathrm{Al}$ interface needs to be higher than the melting temperature of the aluminum but lower than that of the steel. This way the Fe-Al reaction is lower than it would be if both metals were mixed in liquid state. For the success of this technique it is important to position the plates with virtually zero gap. This way, the heat transfer between both plates is more efficient and the repeatability of the experiments is improved. The clamping system is then a key element in this laser welding technique and therefore, a 3D model was made to ensure that it would comply with the requirements (see Fig. 2).
The pressure applied on the plates was produced by the bolts positioned on the upper part of this device. Using a torque wrench to tight the bolts it was possible to ensure identical pressure in different experiments and thus, ensuring repeatability of the results.

\subsection{Metallurgical and Mechanical Characterization}

After welding, three specimens were machined from the welded plates. Two specimens were used for microstructural observations and metallurgical analysis while the other was used for mechanical testing.

The cross-sections of the samples were polished and then etched with Nital $2 \%$ and Keller's to reveal the steel and aluminum microstructure, respectively. The macrographs

Table 3 System and fundamental material interaction parameters range

\begin{tabular}{|c|c|c|c|c|c|}
\hline \multicolumn{3}{|c|}{ System parameters } & \multicolumn{3}{|c|}{ Fundamental material interaction parameters } \\
\hline $\begin{array}{l}\text { Beam diameter, } \\
D_{\text {beam }}, \mathrm{mm}\end{array}$ & $\begin{array}{l}\text { Power, } \\
P, \mathbf{k W}\end{array}$ & 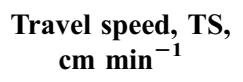 & $\begin{array}{l}\text { Power density, } \\
\text { PD, kW cm }\end{array}$ & $\begin{array}{l}\text { Interaction } \\
\text { time, } t_{\mathrm{i}}, \mathrm{s}\end{array}$ & $\begin{array}{l}\text { Specific point } \\
\text { energy, } E_{\mathrm{sp}}, \mathrm{kJ}\end{array}$ \\
\hline $9.28-14.85$ & $2.55-6.52$ & $19.00-43.00$ & $2.89-7.39$ & $1.29-3.35$ & $5.67-14.52$ \\
\hline
\end{tabular}

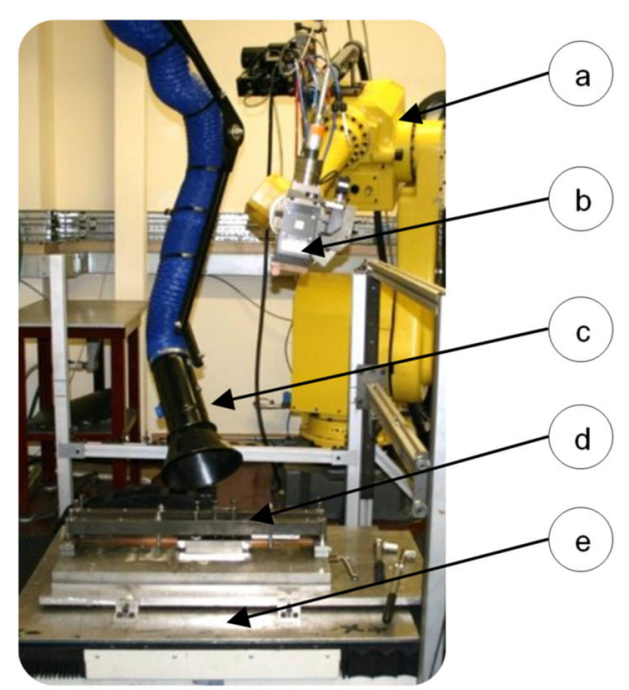

(a) 6 axis Fanuc robot

(b) Laser head (8 $\mathrm{kW}$ fibre laser)

(c) Extraction arm

(d) Clamping system

(e) Gantry system

Fig. 1 Experimental setup used to join steel to aluminum with the laser welding technique
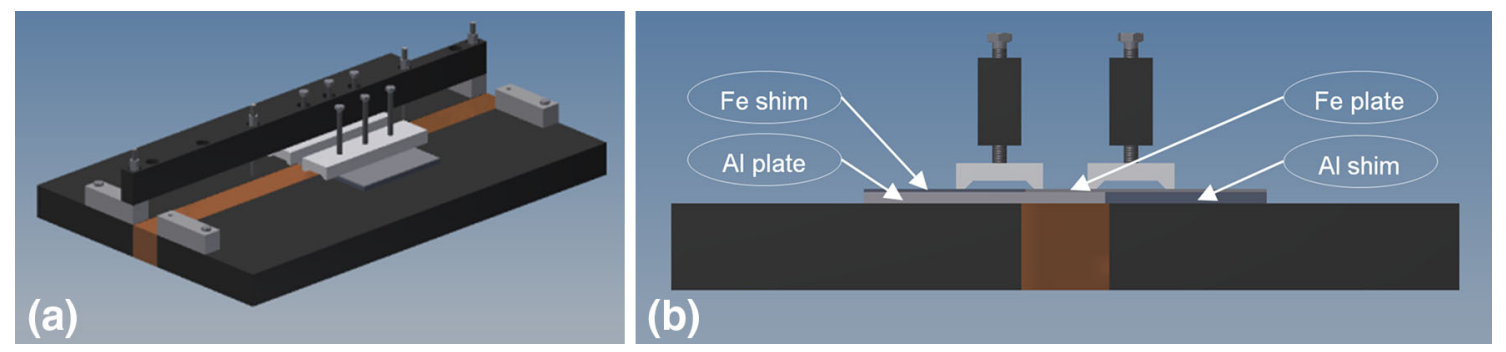

Fig. 2 3D design model of the clamping system used for the laser welding joining of steel to aluminum: (a) isometric view and (b) side view 
showing the weld profiles were taken with a stereo microscope system and the micrographs showing the IM layer were taken with an optical microscope. The approximate atomic composition of the IM layer was determined by energy dispersive spectroscopy (EDS).

To determine the thickness of the IM layer, 11 equidistant micrographs were taken along the cross-section of the weld, only where the IM layer was visible. Then, from each micrograph 21 measurements (equally spaced) were taken from the entire length of the IM layer, using the digital imaging software AxioVision. The average of the 21 measurements was calculated and the highest value was reported.

The strength of the joints was determined by the tensile shear test. The straight sided specimens were $60 \mathrm{~mm}$ wide and $230 \mathrm{~mm}$ long (according to EN ISO 14273:2001 standard). The test was performed at room temperature using the electromechanical Instron 5500R equipment, with a load cell of $100 \mathrm{kN}$. The loading direction was perpendicular to the weld seam and a constant crosshead speed of $1 \mathrm{~mm} \mathrm{~s}^{-1}$ was used. The deformation of the specimens was measured by a laser extensometer (model LE-15) and the gauge length used was $50 \mathrm{~mm}$.

\subsection{Strategy Applied to Assess the Effect of the FMIP on the Fe-AI IM Layer Growth}

The study of the effect of the FMIP on the IM layer growth permits a better understanding of the interaction of the laser with the material, since the FMIP directly correlates the energy input to the IM layer formation.

This work was based on the mathematical expression of the $E_{\text {sp }}$, which is calculated as shown below (see Eq 3).

$E_{\mathrm{sp}}=\mathrm{PD} \times t_{\mathrm{i}} \times A_{\text {beam }}$.

Each term of the $E_{\mathrm{sp}}$ equation (PD, $t_{\mathrm{i}}$, and $A_{\text {beam }}$ ) was tested according to Fig. 3, where $E_{\mathrm{sp}}$ was varied with only one parameter at a time, while the two other were kept constant.
All possible combinations are classified from Case I up to Case III. To keep two terms constant and vary the other two it is necessary to adjust the system parameters accordingly (see Table 4).

For instance in Case I, which represents both $t_{\mathrm{i}}$ and $A_{\text {beam }}$ constant, the $E_{\mathrm{sp}}$ equation can be written in order of the system parameters (Eq 4).

$$
\begin{gathered}
\quad\left\{\begin{array}{l}
E_{\mathrm{sp}}=\mathrm{PD} \cdot t_{\mathrm{i}} \cdot A_{\text {beam }} \\
\mathrm{PD}=P \cdot A_{\mathrm{beam}}^{-1} \\
t_{\mathrm{i}}=D_{\text {beam }} \cdot \mathrm{TS}^{-1} \\
A_{\text {beam }}=0.25 \pi\left(D_{\text {beam }}^{2}\right)
\end{array},\right. \\
\left\{\begin{array} { l } 
{ E _ { \mathrm { sp } } = \text { variable } } \\
{ \mathrm { PD } = \text { variable } } \\
{ t _ { \mathrm { i } } = \text { constant } } \\
{ A _ { \text { beam } } = \text { constant } }
\end{array} \Leftrightarrow \left\{\begin{array} { l } 
{ E _ { \mathrm { sp } } = \text { variable } } \\
{ P = \text { variable } } \\
{ \mathrm { TS } = \text { constant } } \\
{ D _ { \text { beam } } = \text { constant } }
\end{array} \Leftrightarrow \left\{\begin{array}{l}
E_{\mathrm{sp}}=\text { constants } \cdot P \\
P=\text { variable } \\
\mathrm{TS}=\text { constant } \\
D_{\text {beam }}=\text { constant }
\end{array}\right.\right.\right.
\end{gathered}
$$

Equation 4 shows that to perform the experiments in accordance with Case I, laser power was varied while TS and beam diameter were kept constant. $E_{\mathrm{sp}}$ was then a function of $\mathrm{P}$.

An identical approach was applied for Case II where $E_{\text {sp }}$ is variable with $t_{\mathrm{i}}$ (see Eq 5). Thus, in this condition $E_{\mathrm{sp}}$ is only dependent on TS.

$$
\left\{\begin{array}{l}
E_{\mathrm{sp}}=\mathrm{PD} \cdot t_{\mathrm{i}} \cdot A_{\text {beam }} \\
\mathrm{PD}=P \cdot A_{\text {beam }}^{-1} \\
t_{\mathrm{i}}=D_{\text {beam }} \cdot \mathrm{TS}^{-1} \\
A_{\text {beam }}=0.25 \pi\left(D_{\text {beam }}^{2}\right)
\end{array},\right.
$$

$$
\left\{\begin{array} { l } 
{ E _ { \mathrm { sp } } = \text { variable } } \\
{ \mathrm { PD } = \text { constant } } \\
{ t _ { \mathrm { i } } = \text { variable } } \\
{ A _ { \text { beam } } = \text { constant } }
\end{array} \Leftrightarrow \left\{\begin{array} { l } 
{ E _ { \mathrm { sp } } = \text { variable } } \\
{ P = \text { constant } } \\
{ \mathrm { TS } = \text { variable } } \\
{ D _ { \text { beam } } = \text { constant } }
\end{array} \Leftrightarrow \left\{\begin{array}{l}
E_{\mathrm{sp}}=\text { constant } \cdot \mathrm{TS}^{-1} \\
P=\text { constant } \\
\mathrm{TS}=\text { variable } \\
D_{\text {beam }}=\text { constant }
\end{array} .\right.\right.\right.
$$
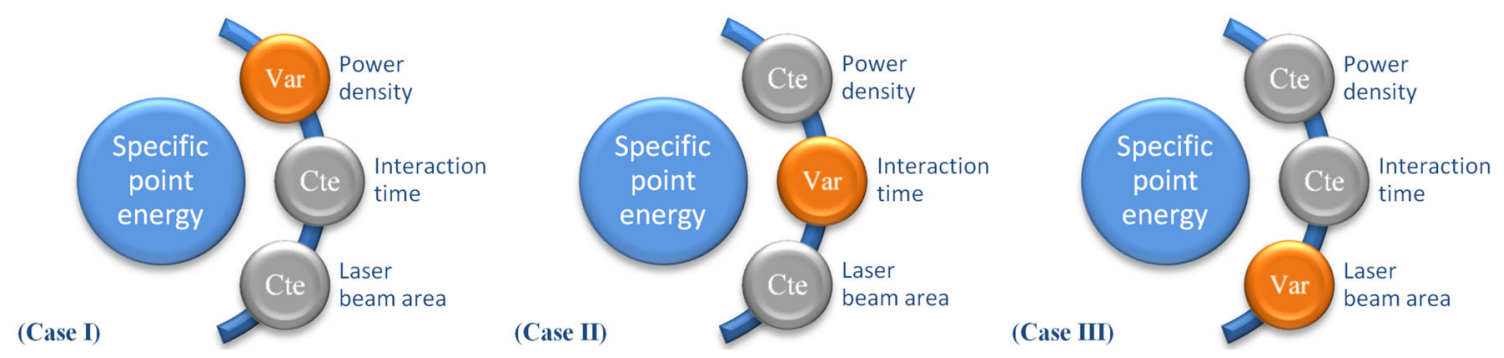

Fig. 3 Schematic representation of the methodology applied on the present study: (Case I) specific point energy variable with PD, (Case II) specific point energy variable with interaction time, and (Case III) specific point energy variable with laser beam diameter

Table 4 Summary of the status of the FMIP and system parameters during the welding experiments: V for variable parameters and $\mathrm{C}$ for constant parameters

\begin{tabular}{lccccccc}
\hline & \multicolumn{3}{c}{ FMIP } & & \multicolumn{2}{c}{ System parameters } \\
\cline { 2 - 7 } & $\boldsymbol{E}_{\text {sp }}$ & PD & $\boldsymbol{t}_{\mathbf{i}}$ & $\boldsymbol{A}_{\text {beam }}$ & & P & TS \\
\hline Case I & $\mathrm{V}$ & $\mathrm{V}$ & $\mathrm{C}$ & $\mathrm{C}$ & & $\mathrm{V}$ & $\mathrm{C}$ \\
Case II & $\mathrm{V}$ & $\mathrm{C}$ & $\mathrm{V}$ & $\mathrm{C}$ & $\mathrm{C}$ & $\mathrm{C}$ \\
Case III & $\mathrm{V}$ & $\mathrm{C}$ & $\mathrm{C}$ & $\mathrm{V}$ & $\mathrm{V}$ & $\mathrm{V}$ \\
\hline
\end{tabular}


When $E_{\mathrm{sp}}$ is variable with $A_{\text {beam }}$ (Case III) the $E_{\mathrm{sp}}$ equation is written as follows:

$$
\begin{gathered}
\left\{\begin{array}{l}
E_{\mathrm{sp}}=\mathrm{PD} \cdot t_{\mathrm{i}} \cdot A_{\text {beam }} \\
\mathrm{PD}=P \cdot A_{\text {beam }}^{-1} \\
t_{\mathrm{i}}=D_{\text {beam }} \cdot \mathrm{TS}^{-1} \\
A_{\text {beam }}=0.25 \pi\left(D_{\text {beam }}^{2}\right.
\end{array}\right) \\
\left\{\begin{array} { l } 
{ E _ { \mathrm { sp } } = \text { variable } } \\
{ \mathrm { PD } = \text { constant } } \\
{ t _ { \mathrm { i } } = \text { constant } } \\
{ A _ { \text { beam } } = \text { variable } }
\end{array} \Leftrightarrow \left\{\begin{array} { l } 
{ E _ { \mathrm { sp } } = \text { variable } } \\
{ P = \text { variable } } \\
{ \mathrm { TS } = \text { variable } } \\
{ D _ { \text { beam } } = \text { variable } }
\end{array} \Leftrightarrow \left\{\begin{array}{l}
E_{\mathrm{sp}}=P \cdot D_{\text {beam }} \cdot \mathrm{TS}^{-1} \\
P=\text { variable } \\
\mathrm{TS}=\text { variable } \\
D_{\text {beam }}=\text { variable }
\end{array}\right.\right.\right.
\end{gathered}
$$

Under such condition, for PD to be constant, $P$ needs to change in the same proportion as $A_{\text {beam }}$ so that the ratio remains constant. As $t_{\mathrm{i}}$ is also constant in this case, TS needs to vary in the same proportion of $D_{\text {beam }}$ so that the ration between these two system parameters remains constant. Thus, for the welding experiments with $E_{\mathrm{sp}}$ variable with $A_{\text {beam }}$ (Case III) all the system parameters ( $\mathrm{P}, \mathrm{TS}$, and $\left.D_{\text {beam }}\right)$ need to be varied simultaneously.

\section{Results and Discussion}

\subsection{Weld Seam Geometry and Fe-AI IM Layer Characterization}

The macrosections of the samples were analyzed to verify not only the presence of defects such as porosity or cracking, but also to ensure that the steel on the interface remained in solid state during the joining process. Figure 4(a) shows a macrograph of one of the samples where the fusion zones in the steel and aluminum plates are visible and no defects are detected. It is observed that the welding process was in conduction mode due to the small depth/width ratio and also the hemispherical geometry of the fusion zone. The IM layer formed between the steel and aluminum plates is usually continuous and thicker in the center of the weld. The optical micrograph shown in Fig. 4(b) indicates that the IM layer formed between the steel and aluminum plates is composed by two IM compounds. Further analysis using SEM/EDS was done in previous experiments to obtain the chemical composition of these two layers. The results indicated that the most developed layer near the steel side is $\mathrm{Fe}_{2} \mathrm{Al}_{5}$ whereas the thinner layer, near the aluminum is $\mathrm{FeAl}_{3}$.

Figure 5 shows the EDS mapping with the spatial distribution of the elements of $\mathrm{Fe}, \mathrm{Al}$, and $\mathrm{Mg}$. The IM layer corresponds to the high density horizontal band at the center of the image where both $\mathrm{Fe}$ and $\mathrm{Al}$ elements are present.

\subsection{Effect of the FMIP on the IM Layer Growth}

The correlation between the IM layer thickness and $E_{\mathrm{sp}}$ is represented in the next three graphs. Each graph shows the evolution of the IM layer growth when the $E_{\mathrm{sp}}$ increases either when PD (Fig. 6), $t_{\mathrm{i}}$ (Fig. 7), or even the $A_{\text {beam }}$ (Fig. 8) increases.

3.2.1 Case I: $E_{\mathrm{sp}}$ is Variable with PD ( $t_{\mathrm{i}}$ and $A_{\text {beam }}$ Remain Constant), (Fig. 6). Figure 6(a) shows that the increase of $E_{\mathrm{sp}}$ via PD induces a near linear growth of the IM layer. One possible reason for this behavior may be explained by the geometry of the weld (Fig. $6 b$ and c). The penetration depth visible on steel or aluminum plates can give an indication about the temperature experienced at the joint interface. In other words, when a deeper fusion zone is formed during the welding process with higher $\mathrm{PD}$, the temperature at the Fe-Al interface is higher. Therefore, a deeper fusion zone is usually associated with a thicker IM layer.

3.2.2 Case II: $E_{\mathrm{sp}}$ is Variable with $\boldsymbol{t}_{\mathrm{i}}$ (PD and $\boldsymbol{A}_{\text {beam }}$ are Constant), (Fig. 7). Under this welding condition, with $E_{\mathrm{sp}}$ varying in function of the $t_{\mathrm{i}}$, the growth of the IM layer has also linear trend but with a less steeper slope. The reason for this seems to be as shown in the work produced by Kobayashi and Yakou (Ref 3). The growth of the IM layer is fast in the first stage of the formation but after certain thickness the growth becomes sluggish. This is apparently due to the lack of Fe atoms available for the reaction with $\mathrm{Al}$ to produce $\mathrm{Fe}_{2} \mathrm{Al}_{5}$. The author also reported that when the $\mathrm{Fe}_{2} \mathrm{Al}_{5}$ layer stops growing and if the temperature is high enough, the IM layer already formed is consumed to form another IM compound. It is relevant to say that

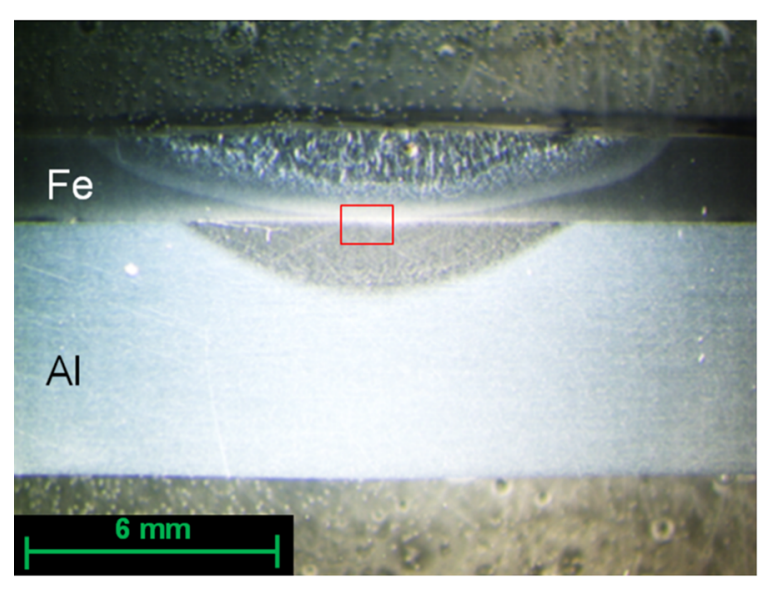

(a)

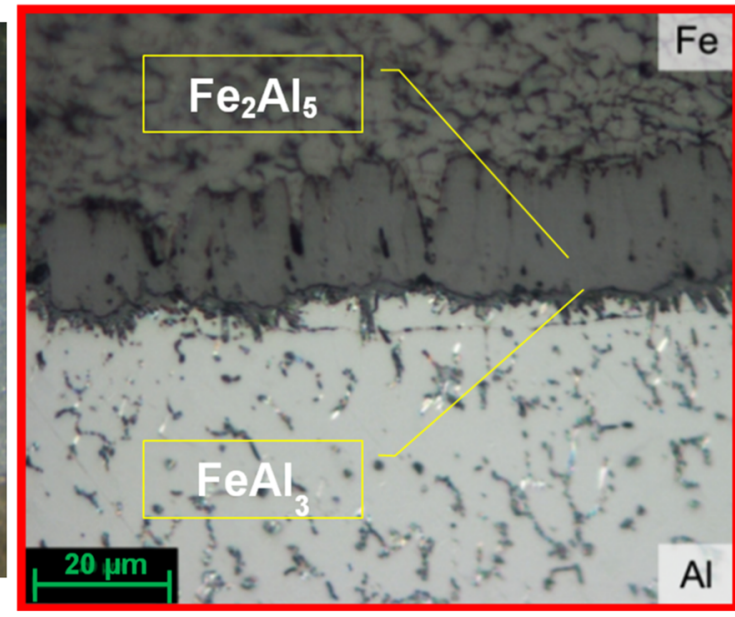

(b)

Fig. 4 Results from the metallographic analysis: (a) macrograph of the Fe-Al dissimilar metal joint and (b) micrograph 


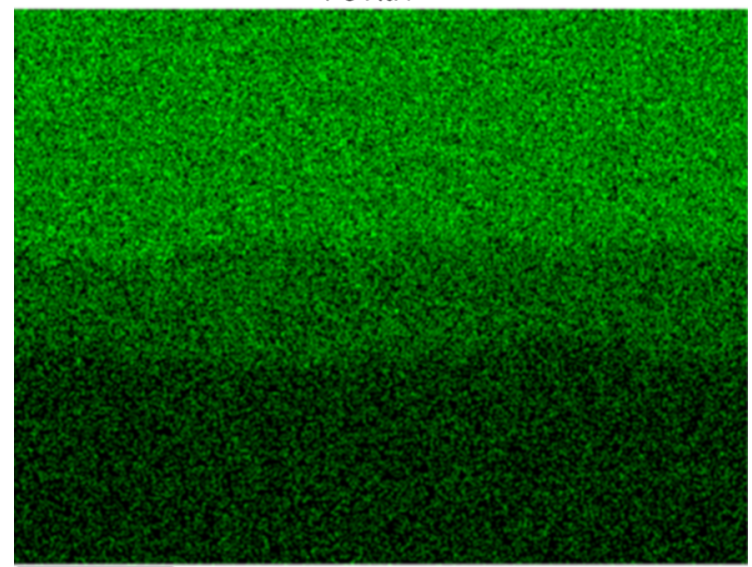

$25 \mu \mathrm{m}$

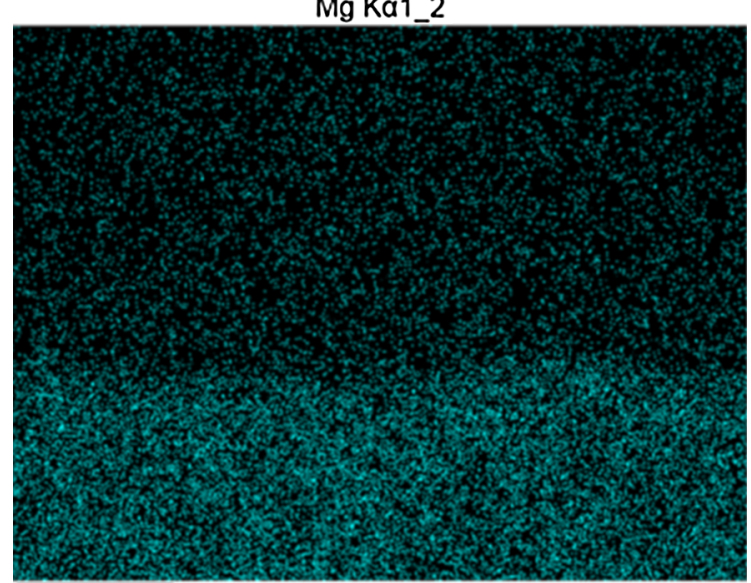

$25 \mu \mathrm{m}$

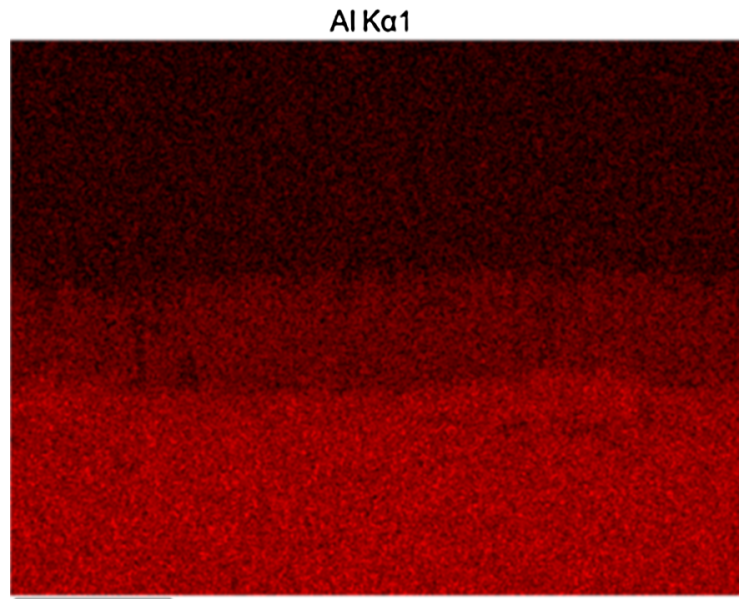

$25 \mu \mathrm{m}$

EDS Layered Image 1

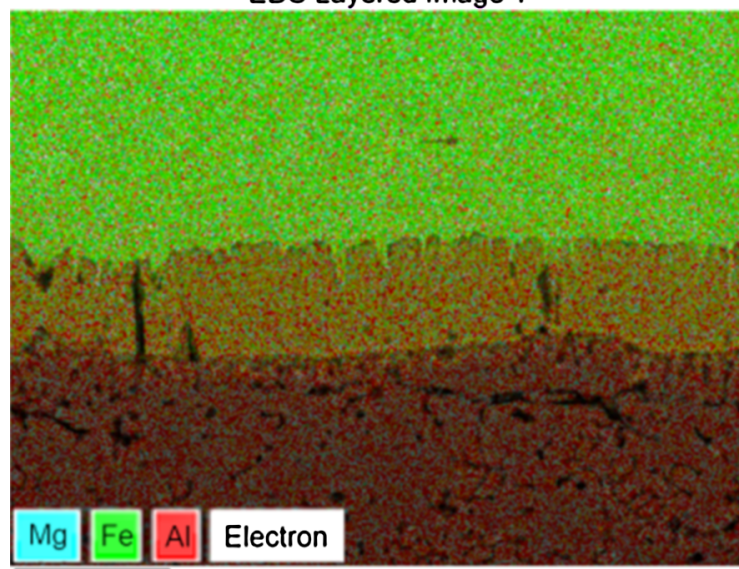

$25 \mu \mathrm{m}$

Fig. 5 EDS mapping showing the spatial distribution of the main constituent elements of the samples: $\mathrm{Fe}, \mathrm{Al}$, and $\mathrm{Mg}$

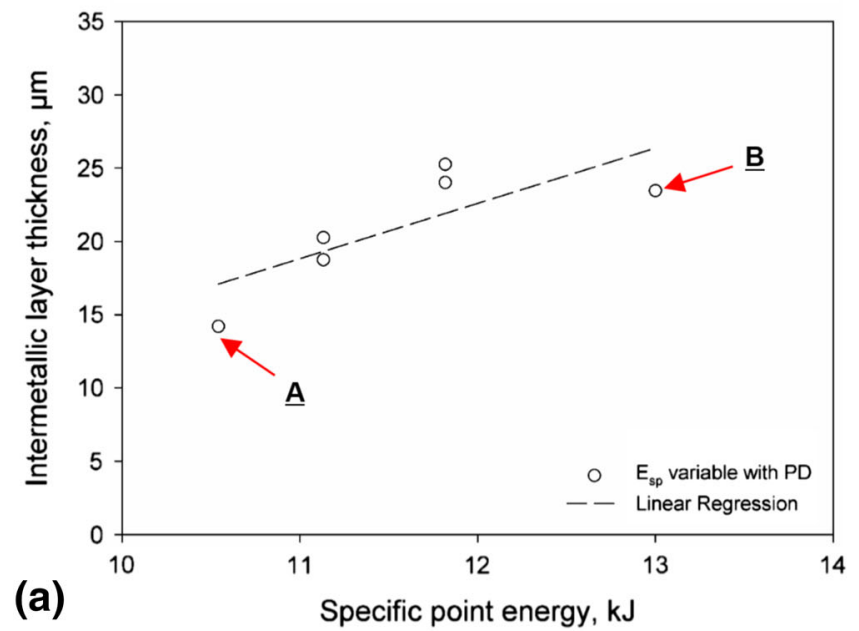

(b)

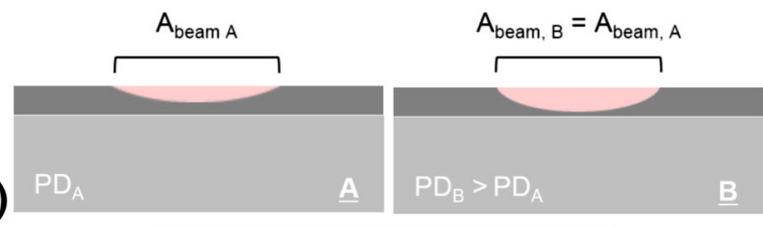

Increase of $E_{s p}$ via $P D$ (case I)
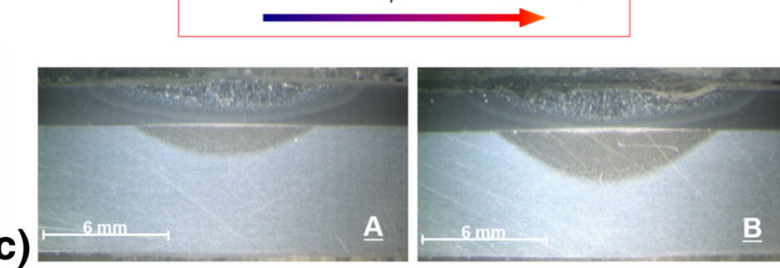

Fig. 6 (a) Correlation between IM layer thickness and $E_{\mathrm{sp}}$ (via PD), (b) schematic representation of the effect of increasing PD on the geometry of the weld, and (c) macroscopic cross-sectional view of the welded samples

the $t_{\mathrm{i}}$ (or heating time) in laser welding is much smaller than the one used in Kobayashi's work and therefore, in the present work there is only limited time for the $\mathrm{Fe}_{2} \mathrm{Al}_{5}$ and $\mathrm{FeAl}_{3}$ to grow and not to transform to any other Fe-Al IM compound.
3.2.3 Case III: $E_{\mathrm{sp}}$ is Variable with $A_{\text {beam }}$ (PD and $t_{\mathrm{i}}$ are Constant), (Fig. 8). The graph in Fig. 8(a) indicates that when $E_{\mathrm{sp}}$ increases via $A_{\text {beam }}$ the IM layer also grows. The weld geometry can be used once again to explain this trend (see 
Fig. $8 \mathrm{~b}$ and $\mathrm{c}$ ). The fusion zone on the steel and $\mathrm{Al}$ plates is deeper when a larger laser beam is used which means that the temperature on the $\mathrm{Fe}-\mathrm{Al}$ interface (where the formation of the IM layer takes place) is higher.

According to Assuncao (Ref 8), the $D_{\text {beam }}$ plays an important role on the penetration depth. The author suggests that for particular welding conditions (which seems to be met in this experimental work since large $D_{\text {beam }}$ and very slow TS are used) the penetration depth increases when $D_{\text {beam }}$ increases (see Fig. $8 \mathrm{~b}$ and c). In this situation, the larger $D_{\text {beam }}$ induces a smaller PD but the penetration level is still higher. The reason for this is attributed to the temperature of the substrate to remain constant, at the vaporization temperature, with the increase of the $D_{\text {beam. }}$. However, there is a point called optimum $D_{\text {beam }}$ which gives the maximum penetration depth from which, the further increase of the $D_{\text {beam }}$ has the opposite effect on the penetration depth. From this point the temperature on the material surface is lower than the vaporization temperature and the decrease of the PD with the increase of the $D_{\text {beam }}$ does not permit the increase in penetration depth. Since in the present

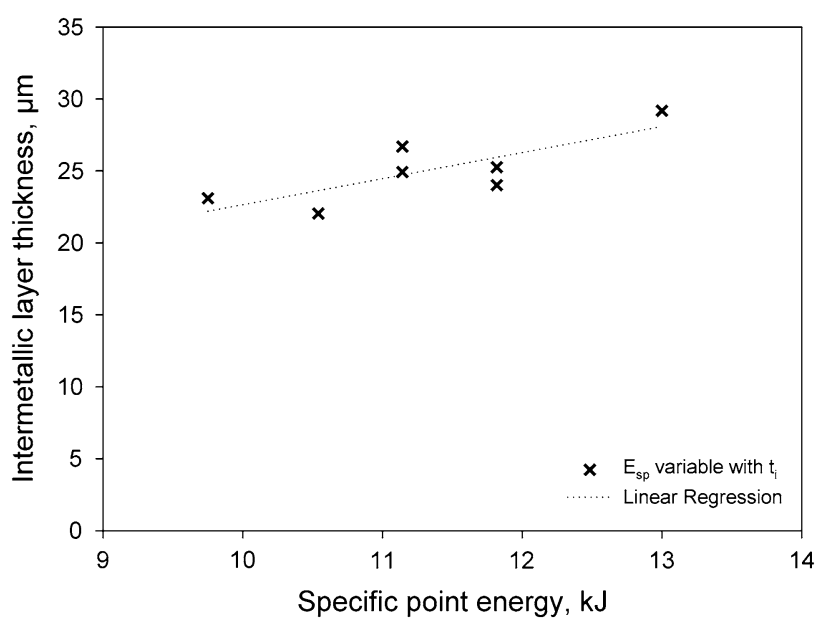

Fig. 7 Correlation between $E_{\mathrm{sp}}$ (via $t_{\mathrm{i}}$ ) and IM layer thickness. $E_{\mathrm{sp}}$ was varied by changing the interaction time

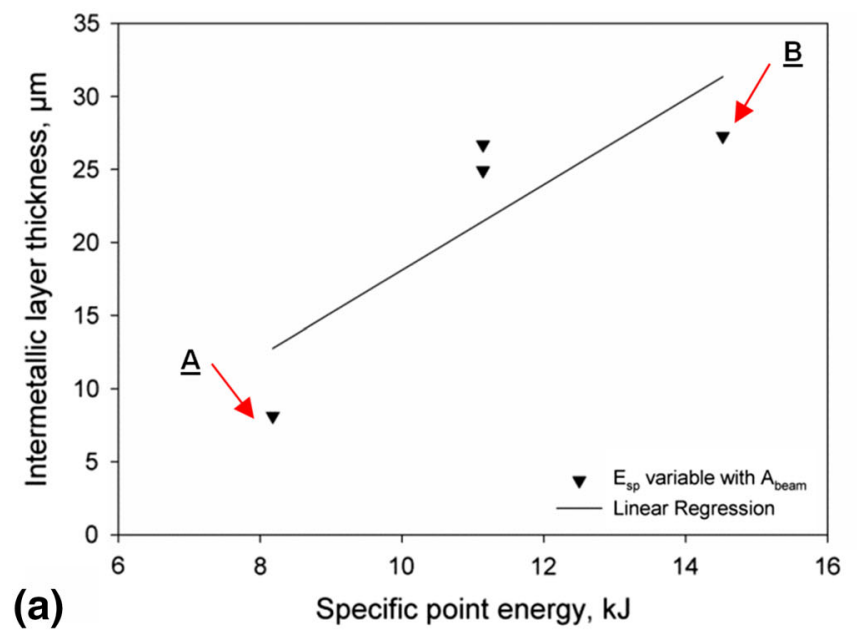

work (in Case III) PD was maintained constant ( $P$ was adjusted in the same proportion as $A_{\text {beam }}$ in order to keep PD constant), it is likely that the critical point was never reached and the penetration depth was always increased.

In general, the increase of the $E_{\mathrm{sp}}$ leads to the growth of the IM layer, independent of the fact that whether it is through increase of PD, $t_{\mathrm{i}}$, or $A_{\text {beam }}$ (see comparison in Fig. 9a). However, if one considers the $E_{\mathrm{sp}}$ ranging between 10 and $13 \mathrm{~kJ}$, the IM layer thickness shows a relatively slower rate of increase with $t_{\mathrm{i}}$ which implies that the diffusion is sluggish in this region (the already formed IM layer prevent further interdiffusion of atoms and the growth becomes sluggish). This phenomenon is explained in details in Fig. 9, where four points in two different levels of $E_{\mathrm{sp}}$ were considered.

For a lower energy level, around $10.5 \mathrm{~kJ}$ (points I and II), the increase in PD results in more melting of the aluminum and thereby, create a larger bonding area (the variation in fusion zone width is near $1 \mathrm{~mm}$ ), and the $t_{\mathrm{i}}$ is long enough to permit the wetting process. At a higher energy level, of about $13 \mathrm{~kJ}$ (points III and IV), PD does not contribute toward increase in bond area. This could be attributed to the fact that over a certain energy level and PD, the heat flux reduces which results in lowering in temperature rise. The additional energy is then solely used toward maintaining the temperature at a higher level for longer time and thus helps in progressing diffusion which will increase the IM layer thickness. Similarly, over a certain level energy and $\mathrm{PD}$, if $t_{\mathrm{i}}$ is too long, the additional energy is used to feed the reaction between Fe and $\mathrm{Al}$ and the IM layer becomes thicker. In summary, when the energy and PD is less than a critical limit, the wetting of steel by molten aluminum is insufficient, as illustrated by point II and, $t_{\mathrm{i}}$ does not have a significant effect on the IM layer growth and even though PD does, as illustrated by point I, the larger bonding area formed balances the presence of the IM compounds. On the other hand, over a critical energy and PD level, increasing the $t_{\mathrm{i}}$ can become extremely detrimental to the joint strength as shown by point III.

\subsection{Mechanical Tensile Shear Strength}

The results of the mechanical tensile shear strength tests are plotted in the graphs illustrated in Fig. 10. The tensile shear

(b)

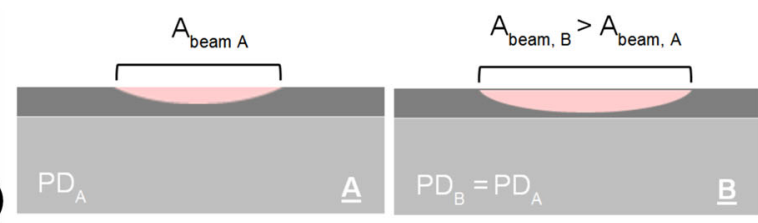

(c)
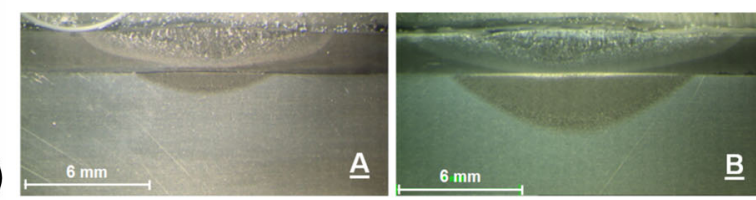

Fig. 8 (a) Correlation between IM layer thickness and $E_{\text {sp }}$ (via $A_{\text {beam }}$ ), (b) schematic representation of the effect of increasing $A_{\text {beam }}$ on the geometry of the weld, and (c) macroscopic cross-section view of the welded samples 


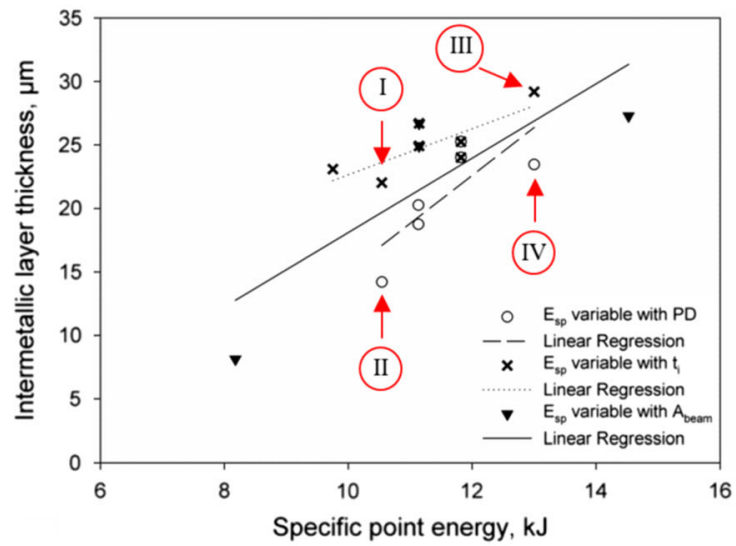

(a)

\begin{tabular}{lllllll}
\hline Point id & $\mathrm{E}_{\text {sp, }}$ kJ & $\begin{array}{l}\text { PD, } \\
\text { kW.cm }\end{array}$ & $\mathrm{t}_{\mathrm{i}}, \mathrm{S}$ & $\begin{array}{l}\text { IM layer } \\
\text { thickness, } \boldsymbol{\mu m}\end{array}$ & $\begin{array}{l}\text { Tensile shear } \\
\text { strength, } \mathrm{N} . \mathrm{mm}^{-1}\end{array}$ & $\begin{array}{l}\text { Bonding } \\
\text { width, } \mathbf{m m}\end{array}$ \\
\hline I & 10.54 & 3.77 & 2.11 & 22 & 498 & 9.68 \\
II & 10.54 & 3.36 & 2.36 & 14 & 107 & 8.86 \\
III & 13.00 & 3.77 & 2.60 & 29 & 83 & 10.78 \\
IV & 13.00 & 4.14 & 2.36 & 23 & 478 & 10.88 \\
\hline
\end{tabular}

Fig. 9 (a) Comparison of the correlation between $E_{\mathrm{sp}}$ (via PD, $t_{\mathrm{i}}$, and $A_{\text {beam }}$ ) and IM layer thickness, (b) details of the highlighted points

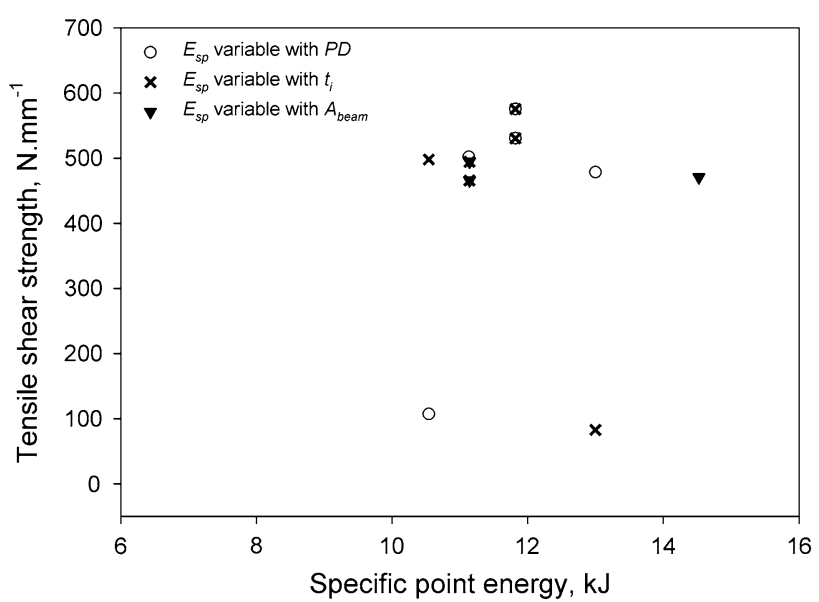

Fig. 10 Correlation between $E_{\mathrm{sp}}$ (via $\mathrm{PD}, t_{\mathrm{i}}$, and $A_{\text {beam }}$ ) and tensile shear strength

strength obtained by dividing the tensile load by the crosswelded specimen width (or, weld length) was found to be in the range between 83 and $575 \mathrm{~N} \mathrm{~mm}^{-1}$ (equivalent to 4 and $30 \mathrm{kN}$ ).

Even though during the mechanical test the failure of all samples was always located at the Fe-Al interface, the specimen experienced some plastic deformation. Figure 11 shows the curve of strain versus tensile shear strength of the specimen with maximum tensile load registered (the FMIP used to weld this sample are mentioned below).

The IM compounds formed between the $\mathrm{Fe}$ and $\mathrm{Al}$ are known for their brittleness $\left(1200 \mathrm{HV}_{0.025 / 10}\right.$ was the hardness measured on the $\mathrm{Fe}_{2} \mathrm{Al}_{5}$ IM layer) and so this layer should be kept to a minimum thickness for better structural integrity. However, the results of the mechanical tensile shear strength tests indicate that mechanical strength and IM layer thickness

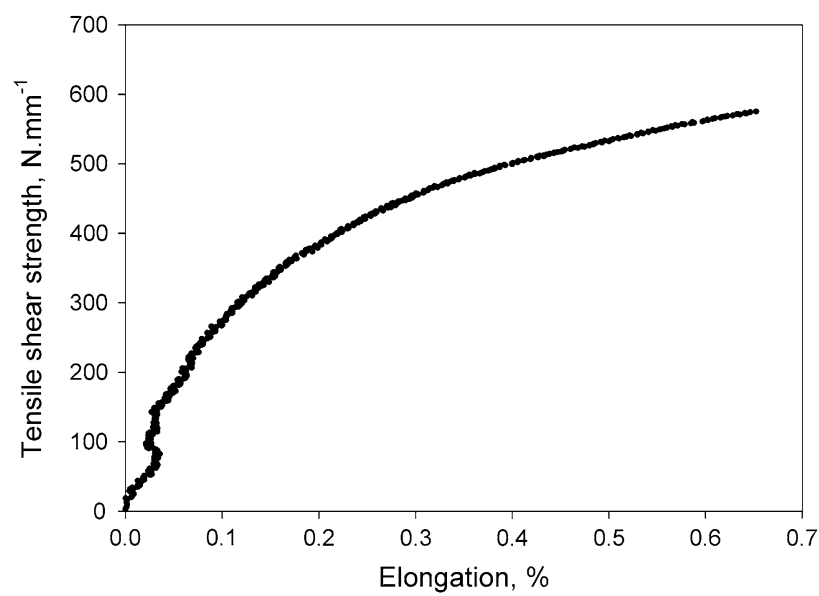

Fig. 11 Tensile shear strength vs. strain for the specimen with highest strength. The FMIP used were $E_{\mathrm{sp}}=11.82 \mathrm{~kJ}$, $\mathrm{PD}=3.77 \mathrm{~kW} \mathrm{~cm}{ }^{-2}, t_{\mathrm{i}}=2.36 \mathrm{~s}$, and $A_{\text {beam }}=1.33 \mathrm{~cm}^{2}$

could not be directly correlated. In other words, the mechanical strength does not increase as the IM layer becomes thinner. This may be explained by the fact that when the welding conditions induce the formation of a thicker IM layer, the wetting area of the $\mathrm{Al}$ on the Fe surface also increases, which contributes to a stronger joint. Due to these opposing facts, the maximum strength of the specimens produced under different joining conditions seems to be of a constant level.

The strength of the dissimilar metal joints for automotive applications has been correlated with the IM layer thickness by many authors who have referred the optimum thickness range to be up to $10 \mu \mathrm{m}(\operatorname{Ref} 12,13)$. Figure 12 shows that the highest mechanical strength of the specimens is when the IM layer thickness is in the range between 18 and $27 \mu \mathrm{m}$. Even 
though in the present work only few samples had IM layer thickness less than $15 \mu \mathrm{m}$, it seems that the optimum thickness for the IM layer is not any unique value. Moreover, the mechanical strength is not only dependent on the IM layer thickness but also dependent on the area of contact between the two plates resultant from the joining process. This may be the reason for the presence of the two points with the lowest strength in Fig. 12. For the minimum value of IM layer thickness (about $15 \mu \mathrm{m}$ ), the area of contact is small to produce a strong joint. On the other hand, when there is a large area of contact between the two metals, the IM layer is very thick (about $30 \mu \mathrm{m}$ ) and the joint is brittle. In this situation the brittleness of the IM layer is more damaging than the increased contact area resulting from the better wetting between the two surfaces. Mathieu et al. (Ref 14) have also suggested that the weld geometry has a significant effect on the joint strength, after some samples with IM layer thickness lower than $10 \mu \mathrm{m}$ had failed on the Fe-Al interface.

It is interesting to compare the mechanical strength of the samples prepared in this experimental work with the strength obtained by other researchers. The maximum mechanical strength measured in this work is similar to the other authors who had their samples failing on the parent material and thus,

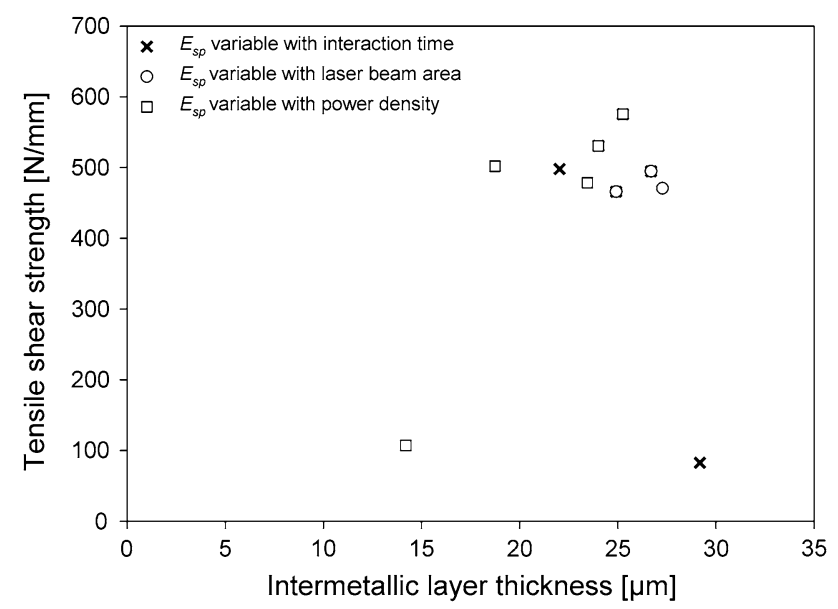

Fig. 12 Dependency of tensile shear strength with the IM layer thickness having successful joints. However, those results are for thin sheets (about $1 \mathrm{~mm}$ thick) whereas in the present work the aluminum and steel plates are 6 and $2 \mathrm{~mm}$ thick, respectively. The interfacial failure of the specimens is possibly related with the lap joint configuration and the material thickness. During the mechanical tensile shear test the lap joint experiences a complex state of stresses, with both shear and bending stresses acting on the joint, because the specimen is not symmetric to the loading. This is observed in the specimens with higher mechanical strength which were bent after the tensile shear test, showing the rotation experienced during the mechanical test (Fig. 13).

Miyazaki et al. (Ref 15) have developed a model to qualitatively predict the position of failure of lap welded steel specimens in tensile shear test, i.e. whether the failure would be from the base metal, near the base metal, or at the weld metal. The equations of the model take into account the rotation experienced during the tensile test and consider the specimen width and thickness as variables. The weld width and length are the other variables. The model predicts that when the dimension of the weld metal width is constant, with increasing thickness the probability of failure from weld metal increases. Therefore, apart from the fact that more energy is required in the joining process of thick plates, which enhances the formation of the IM compounds, it is apparent that a complex loading spectrum due to non-axisymmetric loading would also result into interfacial failure.

\section{Conclusion}

In this work the Fe-Al IM layer growth is correlated with the laser welding process via the FMIPs-PD, interaction time, and specific point energy. The best laser welding condition to minimize the IM layer formation is also discussed. The results of this study indicate:

- Using low energy level, the interaction time does not have a significant effect on the IM layer growth and even though PD does, the larger bonding area formed balances the presence of the IM compounds. On the other hand, for higher energy, interaction time becomes more detrimental to the joint than PD;
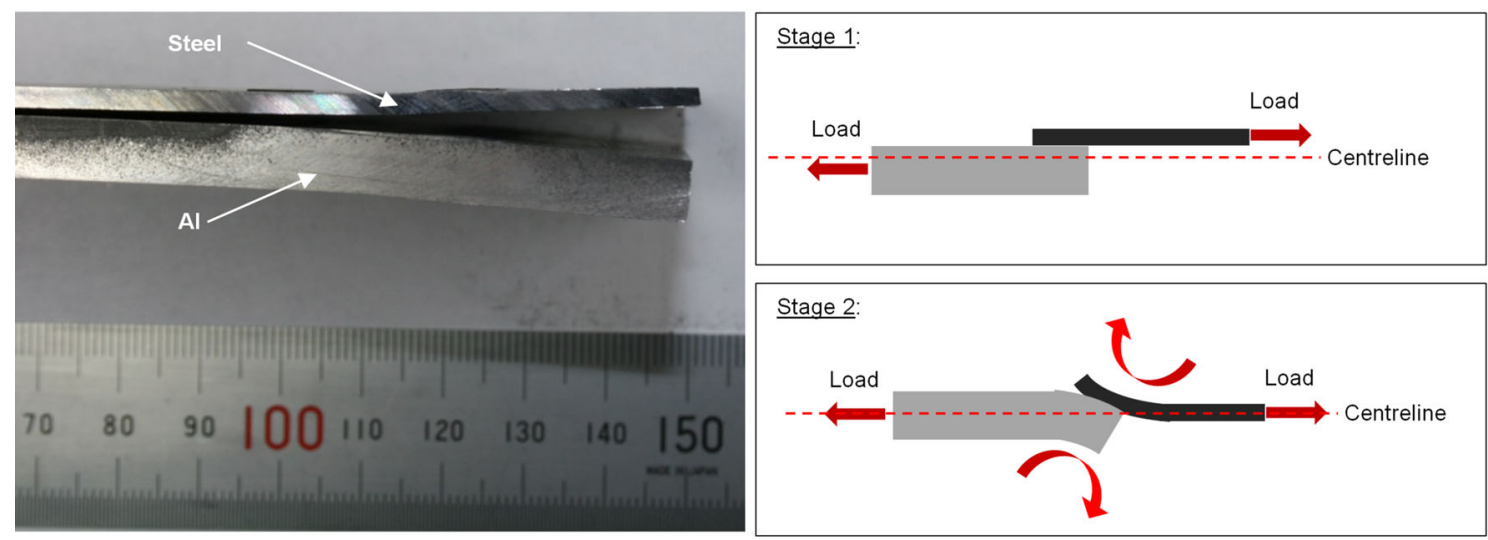

Fig. 13 Detail of the rotation effect caused during the mechanical tensile shear test performed on the lap joint specimen and schematic representation of this effect 
- To maximize the joint strength, the PD should be over a threshold value, which in the experimental domain was found to be about $3.77 \mathrm{~kW} \mathrm{~cm}{ }^{-2}$, to enhance the melting of the aluminum and thus, create a large bonding area. Optimization of interaction time is important as additional interaction would lead to further diffusion and IM growth. In the experimental regime, the optimized interaction time was found to be about $2.11 \mathrm{~s}$;

- The rotational force applied on the lap joint of 6 and $2 \mathrm{~mm}$ plates during the mechanical tensile shear test could be responsible for the interfacial failure of the joint, even when a very thin IM layer is present. Therefore, this joining principle could have better results in thinner plates.

\section{Acknowledgments}

Dr. Supriyo Ganguly acknowledges the support by EPSRC through Grant Number EP/J017086/1. Sonia Meco is grateful to BAE Systems Naval Ships for providing financial support to this project.

\section{References}

1. E. Taban, J.E. Gould, and J.C. Lippold, Dissimilar Friction Welding of 6061-T6 Aluminum and AISI, 1018 Steel: Properties and Microstructural Characterization, Mater. Des., 2010, 31(5), p 2305-2311

2. K. Bouche, F. Barbier, and A. Coulet, Intermetallic Compound Layer Growth Between Solid Iron and Molten Aluminium, Mater. Sci. Eng. A, 1998, 249(1-2), p 167-175
3. S. Kobayashi and T. Yakou, Control of Intermetallic Compound Layers at Interface Between Steel and Aluminum by Diffusion-Treatment, Mater. Sci., 2002, 338, p 44-53

4. R. Borrisutthekul, T. Yachi, Y. Miyashita, and Y. Mutoh, Suppression of Intermetallic Reaction Layer Formation by Controlling Heat Flow in Dissimilar Joining of Steel and Aluminum Alloy, Mater. Sci. Eng. A, 2007, 467(1-2), p 108-113

5. P. Pl, Explosion-Bonded Transition Joints for Structural Applications, Building, 1989, 3(2), p 64-72

6. F. Findik, Recent Developments in Explosive Welding, Mater. Des., 2011, 32(3), p 1081-1093

7. G. Çam and M. Koçak, Progress in Joining of Advanced Materials_-Part 1: Solid State Joining, Fusion Joining, and Joining of Intermetallics, Sci. Technol. Weld. Join., 1998, 3(3), p 105-126

8. E. Assuncao, Investigation of Conduction to Keyhole Mode Transition, Cranfield University, 2012

9. J. Fan, C. Thomy, and F. Vollertsen, Effect of Thermal Cycle on the Formation of Intermetallic Compounds in Laser Welding of Aluminum-Steel Overlap Joints, Phys. Procedia, 2011, 12, p 134-141

10. W.J. Suder and S. Williams, Power Factor Model for Selection of Welding Parameters in CW Laser Welding, Opt. Laser Technol., 2014, 56, p 223-229

11. E. Assuncao, S. Williams, and D. Yapp, Interaction Time and Beam Diameter Effects on the Conduction Mode Limit, Opt. Lasers Eng., 2012, 50(6), p 823-828

12. E. Schubert, D.I. Zerner, and P.G. Sepold, Lasers Material Processing, Proc. SPIE, 1997, 3097, p 212-221

13. H. Ozaki and M. Kutsuna, Laser-Roll Welding of a Dissimilar Metal Joint of Low Carbon Steel to Aluminium Alloy Using $2 \mathrm{~kW}$ Fibre Laser, Weld. Int., 2009, 23(5), p 345-352

14. A. Mathieu, R. Shabadi, A. Deschamps, M. Suery, S. Matte1, D. Grevey, and E. Cicala, Dissimilar Material Joining Using Laser (Aluminum to Steel Using Zinc-Based Filler Wire), Opt. Laser Technol., 2007, 39, p 652-661

15. Y. Miyazaki and S. Yasunobu, Tensile Shear Strength of Laser Welded Lap Joints, Nippon Steel Tech. Rep., 2007, 95, p 28-34 